\title{
Crenças e percepções dos futuros investidores: um contributo para os Estudos Sociais em Finanças
}

Beliefs and Perceptions of Future Investors: A Contribution to Social Studies in Finance

Croyances et perceptions des futurs investisseurs: une contribution aux

tudes Sociales en Finance

Júlio Lobão

\section{OpenEdition}

\section{Journals}

Edição electrónica

URL: http://journals.openedition.org/rccs/8421

DOI: $10.4000 /$ rccs.8421

ISSN: 2182-7435

Editora

Centro de Estudos Sociais da Universidade de Coimbra

Edição impressa

Data de publição: 1 maio 2019

Paginação: 25-52

ISSN: 0254-1106

Refêrencia eletrónica

Júlio Lobão, « Crenças e percepç̃es dos futuros investidores: um contributo para os Estudos Sociais em Finanças », Revista Crítica de Ciências Sociais [Online], 118 | 2019, posto online no dia 26 abril 2019, consultado o 19 março 2020. URL : http://journals.openedition.org/rccs/8421 ; DOl : https://doi.org/ $10.4000 /$ rccs. 8421

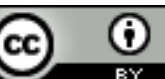




\title{
JÚLIO LOBÃO
}

\section{Crenças e percepções dos futuros investidores: um contributo para os Estudos Sociais em Finanças*}

As crenças e percepções dos indivíduos que estão prestes a iniciar a sua actividade de investimento nos mercados financeiros têm sido uma matéria pouco explorada pela Sociologia das Finanças. Neste artigo apresentamos nova evidência acerca das opiniões dos futuros investidores, recorrendo a um questionário distribuído a um grupo de 177 estudantes universitários entre os anos 2014 e 2016. Os resultados obtidos sugerem que os indivíduos têm percepções inconsistentes acerca dos mercados financeiros, evidenciando-se igualmente um conflito entre a necessidade abstracta de regulação e as consequências subjectivas decorrentes da aplicação das práticas regulatórias.

Palavras-chave: inquérito sociológico; investimento; mercados financeiros; regulação económica; Sociologia das Finanças.

\begin{abstract}
Se queremos compreender as razões para a actuação de alguém - ou seja, se quisermos explicar as suas acções - a primeira coisa que necessitamos de conhecer será o seu próprio ponto de vista acerca dos factos com que se confronta, as suas crenças acerca desses factos, as suas capacidades e esquemas conceptuais, os seus motivos, os seus antecedentes, e claro, o assunto com o qual está a tentar lidar. ${ }^{1}$
\end{abstract}

Mary Midgley (2004: 77)

\section{Introdução}

A forma como os actores sociais imaginam o mundo determina o que pensam que é importante, o que seleccionam como centro da atenção entre a miríade de factos a que constantemente estão expostos. Apenas após essa selecção podem começar a formar pensamentos e descrições (Midgley, 2004).

\footnotetext{
* Por vontade do autor, este artigo não segue as regras do Acordo Ortográfico de 1990.

1 Todas as traduções são do autor.
} 
Como encaram os futuros investidores os mercados financeiros? Julgam que os preços dos activos financeiros são imprevisíveis e excessivamente voláteis ou, pelo contrário, pensam ser possível obter rendibilidades elevadas de forma sistemática? Será que vêem os mercados financeiros como algo socialmente útil? Ou preferem que esses mercados sejam mais fortemente regulados? Pouco se sabe acerca destas importantes questões.

Neste artigo examinam-se as crenças e percepções dos futuros investidores em relação os mercados financeiros através de um conjunto de 177 questionários distribuídos aos estudantes do Mestrado em Finanças na Faculdade de Economia da Universidade do Porto, em Portugal, entre os anos de 2014 e de 2016. O trabalho desenvolvido neste artigo segue o programa da Sociologia das Finanças (MacKenzie, 2006; Carruthers e Kim, 2011), contribuindo para esta corrente da literatura.

$\mathrm{O}$ crescimento do investimento baseado na internet e o desenvolvimento do sector de serviços financeiros tem vindo a facilitar, ao longo das últimas duas décadas, as actividades dos investidores não-profissionais. Os investidores inexperientes têm-se tornado num importante grupo de participantes de mercado, infelizmente ainda pouco estudado pela Sociologia das Finanças (Vollmer et al., 2009). A sobre-representação de indivíduos com educação de nível superior no universo dos investidores nos mercados financeiros sugere que o estudo das opiniões dos estudantes universitários pode ser importante para se entender as decisões dos participantes de mercado (Campbell, 2006; Calvet et al., 2007).

Os conceitos metafóricos relativos aos mercados financeiros que são adoptados pelos futuros participantes de mercado têm uma influência marcante na sua actuação; são a matriz de pensamento, o fundo sobre o qual são moldados os seus hábitos mentais, proporcionando as ferramentas com que se pode organizar a informação acerca dessa instituição social que é o mercado financeiro. A formação de opiniões pressupõe o processamento cognitivo da informação disponível. Ora, no quadro da literatura sobre o tema, é usual identificar-se dois tipos de processamento cognitivo: um processamento paralelo e um processamento heurístico da informação. No processamento paralelo considera-se que o sistema cognitivo é capaz de assegurar o tratamento exaustivo e em contínuo de vastas quantidades de informação. Já no caso da computação heurística, assume-se que os indivíduos, de modo intuitivo e relativamente automático, processam a informação de forma associativa e sequencial adoptando regras de decisão simplificadas que atendem apenas a algumas parcelas dessa informação e à estrutura do ambiente onde a escolha tem lugar (Gardner, 1985; Simon, 1996).

No quadro do presente artigo assumimos que as crenças dos futuros investidores acerca dos mercados financeiros se referem às suas opiniões sobre 
essas instituições e sobre as características dos preços aí gerados. A importância das crenças adoptadas pelos atores sociais que participam nos mercados financeiros pode ser percebida, pelo menos, em três planos. Em primeiro lugar, existem as consequências para os próprios agentes. Por exemplo, se um futuro investidor crê que os mercados financeiros são pouco voláteis, estará disposto a ter uma maior participação no mercado. Essa escolha poderá acarretar perdas quando o investidor se vir confrontado com situações que contrariam a sua expectativa inicial. A este respeito, é ainda de notar que, ao contrário do que é recomendado pela teoria financeira neoclássica, os estudos empíricos mostram que os investidores menos experientes detêm carteiras pouco diversificadas (Goetzmann e Kumar, 2008), transaccionam demasiado (Barber e Odean, 2000) e adoptam um comportamento de jogo nos mercados financeiros (Sjöberg e Engelberg, 2009). Existem também evidências substanciais de que as rendibilidades desse tipo de investidores são anormalmente baixas (Barber et al., 2009). Por tudo isto, entender as perspectivas que esses investidores têm sobre as suas próprias decisões é de capital importância.

Em segundo lugar, as crenças dos investidores trazem consequências para o próprio mercado. No quadro dos Estudos Sociais em Finanças, o argumento da performatividade (Callon, 1998, 2007; MacKenzie e Millo, 2003; MacKenzie, 2006) tem permitido entender o papel central das percepções dos actores sociais - neste caso, investidores - na criação dos mercados financeiros. A teoria da performatividade afirma que os modelos conceptuais adoptados pelos agentes participam na criação desses mercados.

Por último, é necessário identificar os conceitos adoptados pelos actores sociais porquanto esses conceitos, quando errados, podem ter consequências deletérias para o bem-estar social. O papel na crise financeira de 2007/2008 da (errada) percepção de que os mercados de capitais tendem necessariamente para uma situação de equilíbrio constitui, porventura, um dos melhores exemplos do que acabamos de descrever (Shefrin e Statman, 2012).

É por todos estes motivos que é importante para o cientista social atender à formação e estabilização dos conceitos relativos aos mercados financeiros. Neste assunto, os inquéritos de opinião podem proporcionar conhecimentos importantes.

De Bondt (2005) levou a cabo um dos poucos estudos no âmbito da Sociologia das Finanças sobre as crenças dos investidores individuais. Recorrendo a inquéritos a investidores provenientes de seis países europeus (Bélgica, Reino Unido, França, Alemanha, Itália e Espanha), o autor conclui que os "enquadramentos mentais" dos indivíduos são partilhados pelos elementos do mesmo grupo social. As suas crenças apresentam-se correlacionadas com factores socialmente tão relevantes como a nacionalidade, o género, 
a idade e a religião. Além disso, as suas percepções permitem prever as estratégias de investimento e as escolhas de carteira adoptadas.

A investigação de De Bondt (2005) incidiu sobre investidores abastados: mais de metade dos respondentes declarou investir entre $100 \mathrm{mil} \mathrm{e}$ um milhão de euros. $\mathrm{O}$ nosso estudo complementa estes resultados ao debruçar-se sobre os investidores que estão prestes a iniciar a sua carreira de investimento nos mercados financeiros.

O que se segue do nosso artigo está organizado em cinco partes. Começaremos, de seguida, por discutir a importância do estudo da percepção dos investidores enquanto reflexo da veiculação institucional de informação, nomeadamente através do sistema educativo (primeiro tópico). Em seguida, o texto examina as implicações da teoria da performatividade enquanto constructo que permite entender a criação dos mercados a partir das crenças dos investidores e da colocação em prática das suas visões acerca da realidade envolvente (segundo tópico). Segue-se a apresentação dos detalhes do questionário que serviu de base à pesquisa empírica (terceiro tópico) e a discussão dos resultados obtidos relativos às percepções dos inquiridos acerca do funcionamento dos mercados financeiros e da sua regulação (quarto tópico). $\mathrm{O}$ artigo termina com as principais conclusões.

\section{Estudantes, narrativas e sistemas de educação}

O estudo das crenças dos estudantes da Ciência Económica é relevante para a Sociologia. É importante compreender que o conhecimento em geral, e o conhecimento económico-financeiro em particular, é cada vez mais avaliado pela sua contribuição para a actividade económica. Tal conhecimento implica geralmente um significativo suporte institucional, conferido desde logo pelo sistema educacional (Rubinson e Browne, 1994). Este suporte é necessário para que o conhecimento se propague numa determinada população e também de geração em geração, ao longo do tempo. As teorias económicas definem padrões de racionalidade e categorias de risco e determinam as regras que subjazem às decisões dos actores sociais. Está hoje bem estabelecido que o sistema educacional, nomeadamente através da educação nos campos da Economia e Finanças serve para gerir identidades e para produzir subjectividades (Ghoshal e Moran, 1996). De facto, a educação económica, ao contribuir para a formação das percepções dos estudantes acerca da composição dos tipos de agentes presentes na economia, pode desencadear respostas estratégicas por parte dos indivíduos. Os estudantes tendem a adoptar comportamentos semelhantes ao dos agentes que estão presentes nos modelos que lhes são veiculados. Os estudos experimentais revelam que o ensino de Economia e Finanças de matriz neoclássica, tipicamente assente no pressuposto ficcional 
de que os agentes são egoístas por natureza, está associado à supressão de comportamentos cooperativos por parte dos estudantes (Frank et al., 1993). Em consequência, a alegação de que as escolas de negócios estão a produzir agentes oportunistas é um dos exemplos mais frequentes nos estudos sociais do que acabamos de referir (Ghoshal, 2005).

Callon (1998) defende que a disseminação pelas instituições económicas dos estudantes de Economia e Finanças é essencial na construção de provas de força que permitam o surgimento e a implantação de argumentos e instrumentos e, por conseguinte, do triunfo de certas formas de enquadramento das questões económicas. Aqueles actores tendem a tornar-se os parceiros e intermediários que permitem que a teoria económica dialogue com os seus praticantes, formatando as suas perspectivas e actuações. Neste sentido, caberá aos cientistas sociais estudar a profissão dos economistas, uma vez que tal profissão é a que produz o conhecimento de que os agentes fazem uso quando desempenham as "funções económicas". Ora, a análise da percepção dos estudantes acerca da realidade económica, em particular daqueles que se encontram mais próximos de tais "funções económicas", é uma das formas mais directas de levar a cabo esse objectivo.

Uma reflexão sobre as percepções dessa camada populacional parece-nos particularmente oportuna numa altura em que a relação entre o conhecimento teórico e o mundo real é mais relevante, dada a maior proporção de pessoas com acesso à universidade e à aprendizagem de teorias e de conhecimentos gerados pelos cientistas sociais. O presente artigo permite perspectivar assim, igualmente, as consequências do acesso de pessoas qualificadas ao mundo real, com a consequente implementação dessas teorias nos negócios quotidianos.

Conhecer as crenças dos investidores é também importante na óptica dos programas de literacia financeira. A generalização da literacia financeira é vista cada vez mais como uma forma de aumentar a participação dos indivíduos nos mercados financeiros, apesar dos dados indicarem que essa participação depende fortemente de factores como o rendimento e o estatuto social dos indivíduos (De Bondt, 2005). Níveis crescentes de literacia são necessários para decidir num ambiente em que as instituições financeiras tendem a defender os seus interesses através da capitalização de assimetrias de informação face aos seus clientes (Lépinay, 2011). É evidente que a questão da literacia financeira se situa no centro da tomada de decisão nesta área. O que sabem realmente os indivíduos acerca dos mercados financeiros? Quando um problema financeiro se coloca perante um potencial investidor, não existe um modelo inequívoco de actuação, embora possam existir diversos graus de conhecimento. Muitas pessoas usam modelos metrológicos 
que não lhes asseguram bons resultados. A discussão acerca dos valores empiricamente mais válidos para orientar um investidor continua acesa no seio da literatura da área das Finanças. Talvez um dos maiores sinais da divisão nesse debate tenha sido a atribuição do prémio Nobel da Economia em 2013 a Eugene Fama e a Robert Shiller, duas personalidades com visões largamente contraditórias acerca do funcionamento dos mercados financeiros.

Segundo McCloskey (1992), as vidas dos actores sociais estão irremediavelmente entrelaçadas em narrativas, em histórias que se escutam e que se contam, e que são retrabalhadas para formar a história que os agentes narram a si próprios. Nesse sentido, os actores sociais vivem imersos em narrativas, as quais, independentemente da sua validade empírica, têm desempenhado um papel central na construção do conhecimento social ao longo da evolução da espécie humana (Boyd, 2010). As narrativas construídas pelos actores sociais funcionam como uma história que integra as parcelas de informação mais importantes de modo a proporcionar as bases para a escolha da melhor heurística de decisão. Esses elementos adaptativos, de que lançam mão também os agentes financeiros, têm sido objecto de estudo pelos cientistas sociais ao longo dos últimos anos nos mais diversos contextos organizacionais e de mercado (Tuckett, 2011; Tarim, 2012). Os estudantes dos mercados financeiros não são excepção: também vivem rodeados da retórica produzida pelo sistema educacional. Ora, o estudo que se apresenta neste artigo proporciona um ponto privilegiado de observação sobre as narrativas adoptadas por esses actores económicos.

\section{Estudantes, teorias e performatividade}

O estudo das concepções dos estudantes de economia acerca dos mercados financeiros é importante no contexto da teoria da performatividade. A performatividade é um conceito-chave no âmbito da Sociologia das Finanças (Callon, 1998, 2007; Boldyrev e Svetlova, 2016). Os conteúdos de Economia Financeira veiculados nas universidades levam a que diversas ideias e fórmulas sejam consagradas nos mercados de capitais na medida em que os actores sociais - no caso, os participantes de mercado - as implementam no terreno e as adoptam como normas de conduta.

O estudo das crenças e percepções dos futuros investidores estabelece um diálogo com as teorias de performatividade. De facto, no seio dessas teorias, os conceitos e modelos da Ciência Económica aceites pelos actores sociais são mais do que meras abstracções, são também constituintes das práticas de mercado e parte da infra-estrutura dos mercados modernos. A economia, conforme defende Callon (1998: 30), "está inserida não na sociedade, mas na Ciência Económica”. A Ciência Económica não descreve 
uma "economia" externa e pré-existente, antes faz com que essa economia se materialize; a Ciência Económica, nesse sentido, cria a economia, dá origem ao fenómeno que descreve.

O surgimento e a aplicação da fórmula de Black-Scholes para avaliação de opções é, porventura, o exemplo mais analisado de performatividade no seio da Sociologia das Finanças. A fórmula de Black-Scholes constitui um modelo matemático de avaliação de opções (instrumentos financeiros derivados) baseado na existência de relações de equilíbrio entre mercados financeiros e que foi desenvolvida pelos economistas Fischer Black e Myron Scholes no início dos anos 70 do século passado (Dineen, 2013). Em dois artigos fundamentais na área dos estudos sociais em Finanças, Mackenzie e Millo (2003) e MacKenzie (2006) mostram que, após a sua introdução nos mercados financeiros, a fórmula de Black-Scholes foi rapidamente adoptada como um instrumento canónico, apesar de assentar em pressupostos errados. Não obstante, ao longo dos anos 70 observou-se um ajustamento crescente entre os preços previstos pelo modelo e os preços de mercado. O modelo tornou-se bem-sucedido não porque se tenha descoberto o padrão de preços pré-existentes à sua aplicação, mas porque os mercados, em consequência da adopção generalizada da fórmula, tornaram mais precisos os pressupostos do modelo. Dito de outra forma, a força do modelo residiu na sua força prescritiva, não na sua veracidade descritiva.

Em princípio, qualquer crença ou interpretação acerca da formação dos preços pode tornar-se performativa se os agentes dela fizerem uso, através da sua actuação no mercado. Essa aplicação é especialmente importante no caso dos investidores com maiores conhecimentos em Finanças, como no caso dos estudantes dessa área de conhecimento. De facto, um dos resultados mais robustos na literatura de literacia financeira é o de que os indivíduos com maiores conhecimentos financeiros tendem a ter uma maior participação nos mercados financeiros (Yoong, 2011; Arrondel et al., 2012; Almenberg e Dreber, 2015).

A abordagem da performatividade à análise dos mercados tem sido objecto de diversas críticas. Por exemplo, tem sido salientada a ambiguidade inscrita no próprio conceito de performatividade (Fine, 2003; Mäki, 2013). Alguns autores consideram que a eficácia da Ciência Económica enquanto técnica performativa acaba por ser limitada uma vez que se ignora o factor humano na aprendizagem e na aplicação das teorias (Mäki, 2013). Apesar do postulado pelas teorias económicas, os agentes de mercado não podem deixar de incorporar nas suas decisões os conceitos morais, as normas e os valores vigentes na sociedade em que se integram (Santos e Rodrigues, 2009). Por isso, alguns autores concluem que a força performativa dos modelos económicos é muito variável, o que pode conduzir a discrepâncias significativas 
entre o que é previsto por esses modelos e as realidades sociais verificadas empiricamente (Fine, 2003; Aspers, 2007; Santos e Rodrigues, 2009).

A assunção do argumento da performatividade levanta também questões centrais no domínio da responsabilidade ética, tanto dos agentes utilizadores dos modelos económico-financeiros como daqueles que contribuem para os propagar. Por um lado, o entendimento de que a verdade financeira é constituída através da performatividade significa que os participantes das instituições financeiras carregam consigo a responsabilidade (colectiva) pelas condições em que operam no que respeita, por exemplo, à volatilidade dos preços ou às desigualdades de rendimento geradas pelas práticas de mercado contemporâneas. Mas, por outro lado, é importante perceber a dimensão da teoria da performatividade enquanto crítica aos resultados da aplicação dos modelos dominantes. O debate acerca do alcance desta dimensão crítica continua bem vivo na literatura com um grupo de autores a defender que a perspectiva da performatividade se tem revelado demasiado conformista em relação às falsas abstracções utilizadas pelos economistas (Miller, 2002; Mirowski e Nik-Khah, 2007, 2008).

Em qualquer caso, a teoria da performatividade realça a natureza eminentemente histórica dos processos económicos. As regularidades, decorrentes da estabilização de determinadas formas de organização das relações de mercado, permanecem limitadas no tempo e no espaço. A Ciência Económica tem poder porque, ao contrário da Física, pode - em princípio - influenciar a economia através do comportamento dos atores sociais. Mas a Ciência Económica é também débil no sentido de que não é capaz de exercer essa influência a todo o momento e em todos os espaços económicos. Não existem leis naturais nos mercados, apenas leis temporárias e mutáveis que podem ser associadas a determinados mercados específicos em certas circunstâncias históricas. Compreender as Finanças como uma prática performativa sugere que os processos de conhecimento e interpretação não só não são de importância secundária, como são precisamente a forma como as Finanças se materializam. Não se dá apenas o caso de o conhecimento financeiro ser construído socialmente; são as próprias estruturas materiais dos mercados financeiros - incluindo preços, custos e capital - que são constituídas de forma discursiva e historicamente contingente. Por isso, uma das principais implicações do conceito de performatividade é a de que é relevante estudar a medida em que os conceitos, noções ou teorias são aceites pelos actores sociais. É precisamente isso que se pretende levar a cabo com o presente estudo.

\section{O questionário}

No presente estudo foi adoptado o método de inquéritos. Os questionários foram distribuídos aos alunos da unidade curricular de Mercados e 
Investimentos Financeiros (MIF) do Mestrado em Finanças da Faculdade de Economia da Universidade do Porto (FEP), em Portugal. Os questionários foram redigidos em Inglês - a língua em que foi leccionada a unidade curricular de MIF - e foram disponibilizados na primeira aula de MIF durante três anos lectivos consecutivos (2014/2015, 2015/2016 e 2016/2017).

Considera-se que o universo dos alunos inscritos na unidade curricular de MIF constitui uma boa aproximação ao grupo dos futuros investidores: em primeiro lugar, trata-se de indivíduos com um notório interesse pelos mercados financeiros: de entre os 15 cursos de $2{ }^{\circ}$ ciclo em funcionamento na FEP, os sujeitos decidiram-se pela inscrição no mestrado mais direccionado para a área das Finanças; e, em segundo lugar, o Mestrado em Finanças da FEP constitui um mestrado de continuidade, o que significa que é dirigido para os alunos que terminaram o primeiro ciclo de estudos e que, por isso, ainda não iniciaram a sua carreira profissional.

O questionário contém um total de oito afirmações em relação às quais os alunos foram convidados a dar a sua opinião no contexto de uma escala Likert com sete níveis (1: discordo completamente, em qualquer situação; 2: discordo fortemente, em quase todas as situações; 3 : tendo a discordar para a maior parte das situações; 4: é difícil dizer; 5 : tendo a concordar para a maior parte das situações; 6 : concordo fortemente, em quase todas as situações; 7: concordo completamente, em qualquer situação). As oito afirmações apresentadas relacionam-se com as concepções dos respondentes quanto ao funcionamento dos mercados financeiros (cinco questões) e quanto às suas perspectivas acerca da regulação dos mercados financeiros (três questões). $\mathrm{Na}$ análise dos resultados, as respostas serão codificadas da seguinte forma: a forte discordância terá o código -3; a discordância moderada terá o código -2; a discordância ligeira terá o código -1; a posição neutral terá o código 0 ; a concordância ligeira terá o código +1 ; a concordância moderada terá o código +2 e a forte concordância assumirá o código +3 .

As primeiras cinco afirmações que compõem o questionário estão relacionadas com pontos centrais da ortodoxia neoclássica das Finanças: equilíbrio, estabilidade e previsibilidade dos preços de mercado.

Fama (1965, 1970), ao estabelecer o conceito de eficiência de mercado, erigiu um dos pilares em que assentam as Finanças Neoclássicas. De acordo com esse autor, os mercados financeiros podem ser entendidos como sendo compostos por um conjunto alargado de investidores racionais que competem entre si para obter mais-valias. A obtenção dessas mais-valias depende da detecção de divergências entre o preço de mercado e o valor intrínseco dos activos. Assim, se os investidores concluírem, a partir da análise da informação disponível, que o preço de mercado é inferior (superior) ao valor intrínseco 
do activo, ou seja, se acharem que o activo se encontra subavaliado (sobreavaliado) pelo mercado, é de esperar que se decidam a comprar (vender) o activo. Na lógica do raciocínio de Fama $(1965,1970)$, esta actuação fará com que o preço do activo reflicta a informação que serviu de base à avaliação do investidor e convirja para o valor intrínseco. Ora, se todos os investidores actuarem desta forma, sem serem limitados por barreiras à transacção, é de esperar que os preços: 1) reflictam em permanência todas as parcelas da informação disponível e 2) constituam a melhor estimativa do valor intrínseco dos activos. Isso significa que o movimento futuro dos preços, ao depender de parcelas de informação que só se tornarão conhecidas num momento ulterior, não pode ser previsto no presente. Dito de outra forma, num mercado eficiente os preços futuros não dependerão dos preços conhecidos no momento actual. É por isso que no quadro das Finanças Neoclássicas se refere que os preços de um mercado competitivo devem seguir o chamado "passeio aleatório".

A primeira afirmação do questionário ("Os mercados financeiros tendem para um estado de equilíbrio") foca-se no processo de formação dos preços de mercado. Para os estudantes, os preços seguem a lógica do que é postulado pela teoria neoclássica (ou seja, convergem para um dado ponto de equilíbrio) ou, pelo contrário, não têm qualquer significado à luz desses princípios? Se a primeira afirmação incide sobre o trajecto dos preços, a segunda proposição ("Os preços dos mercados financeiros reflectem o valor dos activos") pretende colocar em evidência o ponto de destino dos preços no quadro da teoria financeira ortodoxa. Já as três proposições seguintes ("Os mercados financeiros exibem um conjunto de padrões previsíveis"; "É possível prever vão os mercados financeiros evoluir num período de dias ou semanas"; "É possível prever como vão os mercados financeiros evoluir num período de meses ou anos") atendem à noção de que os preços de um mercado competitivo deverão seguir um "passeio aleatório", não sendo por isso passíveis de serem antecipados pelos investidores.

As últimas três afirmações do questionário distinguem-se das anteriores pelo seu carácter valorativo; pretende-se agora conhecer a opinião dos estudantes acerca do que "devem ser" os mercados financeiros. No quadro da teoria neoclássica, os mercados financeiros desempenham um papel positivo nas economias ao facilitarem a afectação de recursos às oportunidades de investimento real mais produtivas (Levine, 2005). Com a proposição "Os mercados financeiros têm desempenhado um papel positivo na economia do meu país" pretende-se averiguar da adesão a esta tese. Já as últimas duas afirmações ("Os mercados financeiros deveriam ser mais regulados"; "Os impostos sobre mais-valias deveriam ser mais elevados do que os impostos sobre salários”) incidem sobre o papel que as autoridades públicas 
podem desempenhar na regulação dos mercados financeiros com recurso, nomeadamente, a instrumentos de política fiscal na linha dos argumentos que têm sido apresentados por diversos críticos da financialização das economias modernas (Stiglitz, 1993; Stout, 1995).

Para além das oito afirmações, o questionário contém perguntas acerca da experiência de investimento nos mercados de capitais ("Já investiu alguma vez nos mercados financeiros?") e acerca da área em que foi concedido esse grau ("Em que área obteve o seu grau de bacharel/licenciado? Economia, Gestão, Engenharia, etc.).

\section{Resultados do inquérito e respectiva discussão}

Foi recolhido um total de 177 respostas ao inquérito, sendo que um dos estudantes não respondeu às questões relativas à experiência de transacção e ao seu percurso escolar. Dos alunos que forneceram informação a esse respeito, $38(21,6 \%)$ declararam ter tido alguma experiência de investimento nos mercados financeiros, enquanto a larga maioria (138 estudantes, correspondendo a 78,4\% do total) afirmou nunca ter tido essa experiência. $162(92,0 \%)$ estudantes declararam ter realizado a sua formação nas áreas da Economia e Gestão (incluíram-se aqui os cursos de Economia, Gestão, Finanças e Contabilidade) e apenas 14 estudantes ( $8 \%$ ) se apresentaram com uma formação de base numa área fora desses domínios (incluíram-se aqui os cursos de Engenharia, Telecomunicações, Relações Internacionais, Marketing, Administração Pública, Filosofia, Física e Ciência Política).

\section{a) Crenças e percepções acerca do funcionamento dos mercados financeiros}

$\mathrm{Na}$ Tabela 1 apresentam-se os resultados referentes às percepções dos respondentes acerca do funcionamento dos mercados financeiros.

As duas primeiras afirmações dizem respeito à natureza dos preços dos mercados financeiros. É interessante notar as diferenças nas opiniões acerca dessas duas afirmações. Assim, verifica-se que, em geral, os inquiridos acreditam que os mercados financeiros tendem para um estado de equilíbrio (+0,33). Cerca de metade dos estudantes $(49,7 \%)$ é dessa opinião. Já a resposta acerca da capacidade dos mercados financeiros para reflectir o valor dos activos financeiros é vista de forma ambígua pela globalidade dos respondentes: apesar de a resposta mais frequente ser de aprovação, o nível de concordância média é mínimo $(+0,08)$, sendo que a diferença entre os que concordam $(49,7 \%$ ) e os que não concordam $(35,6 \%)$ com a afirmação se situa em 14,1 pontos percentuais.

Os futuros investidores parecem subestimar a importância de fenómenos como as bolhas especulativas, que se traduzem num afastamento severo e 
duradouro (frequentemente durante vários anos) dos preços nos mercados financeiros face aos fundamentais (Shiller, 2015). Na verdade, da conjugação dos resultados relativos às duas primeiras afirmações parece ressaltar que os inquiridos não estão seguros de que, a cada momento, os preços dos activos financeiros estejam correctos, mas crêem que no futuro os preços tenderão para um nível de equilíbrio e, logo, para um valor acertado.

Os resultados seguintes parecem sugerir uma percepção inconsistente da globalidade dos respondentes. A maioria dos indivíduos parece aceitar que os mercados exibem movimentos previsíveis dos preços $(52,0 \%$ de concordâncias versus $26,0 \%$ de opiniões discordantes). A opinião média traduz a concordância geral com a afirmação $3(+0,33)$ e a diferença entre os dois campos é a mais significativa ( 26 pontos percentuais) no conjunto das proposições que constam da Tabela 1. Possivelmente, estes resultados reflectem o conhecimento de anomalias e padrões de evolução de preços de divulgação generalizada, em particular entre os indivíduos mais interessados na temática das Finanças. Referimo-nos, por exemplo, a efeitos sazonais bem descritos na literatura como o efeito Janeiro ou os efeitos associados aos dias da semana (Siegel, 2014).

\section{TABELA 1 - As percepções dos respondentes acerca do funcionamento dos mercados financeiros}

\begin{tabular}{|c|c|c|c|c|c|c|c|}
\hline & Média & Mediana & Moda & Variância & Concorda & Discorda & Diferença \\
\hline $\begin{array}{l}\text { 1. Os mercados financeiros } \\
\text { tendem para um estado de } \\
\text { equilíbrio }\end{array}$ & 0,33 & 0,00 & 1,0 & 1,55 & $49,7 \%$ & $25,4 \%$ & 24,3 p.p. \\
\hline $\begin{array}{l}\text { 2. Os preços dos mercados } \\
\text { financeiros reflectem o valor } \\
\text { dos activos }\end{array}$ & 0,08 & 0,00 & 1,0 & 1,88 & $49,7 \%$ & $35,6 \%$ & 14,1 p.p. \\
\hline $\begin{array}{l}\text { 3. Os mercados financeiros } \\
\text { exibem um conjunto de } \\
\text { padrões previsíveis }\end{array}$ & 0,33 & 1,00 & 1,0 & 1,63 & $52,0 \%$ & $26,0 \%$ & 26,0 p.p. \\
\hline \multicolumn{8}{|l|}{$\begin{array}{l}\text { 4. É possível prever como } \\
\text { vão evoluir os mercados } \\
\text { financeiros ... }\end{array}$} \\
\hline $\begin{array}{l}\text { a. ...num período de dias } \\
\text { ou semanas }\end{array}$ & 0,12 & 1,00 & 1,0 & 1,72 & $52,0 \%$ & $35,0 \%$ & 17,0 p.p. \\
\hline $\begin{array}{l}\text { b. ...num período de meses } \\
\text { ou anos }\end{array}$ & $-0,36$ & 0,00 & 1,0 & 2,02 & $32,8 \%$ & $45,2 \%$ & $-12,4$ p.p. \\
\hline
\end{tabular}


Apesar de acreditarem que os preços manifestam movimentos previsíveis, os inquiridos não parecem estar de acordo acerca do horizonte temporal em que esses movimentos ocorrem. Por um lado, a maioria dos estudantes diz acreditar que é possível prever o modo como os preços vão variar num período de dias ou semanas $(52 \%$ de concordância versus $35 \%$ de opiniões discordantes), mas o nível médio de concordância com a afirmação é muito ténue $(+0,12)$. Por outro lado, o colectivo dos estudantes discorda de que seja possível prever a evolução dos preços num prazo mais longo (meses ou anos); o nível de discordância face à afirmação é o mais forte nas proposições até agora analisadas $(-0,36)$ e as opiniões discordantes ultrapassam as concordâncias em 12,4 pontos percentuais. É ainda interessante verificar, no caso das afirmações $4 a$ e $4 b$, que as opiniões de discordância são invulgarmente fortes (a média é inferior à mediana); além disso, a dispersão nas opiniões dos inquiridos atinge o seu nível mais elevado na reacção à afirmação $4 b$ (o desvio-padrão das respostas é superior a 2). Em resumo: os inquiridos dizem acreditar que a evolução dos preços é previsível, julgam na sua maioria que tal se verifica a curto prazo e discordam que tal se observe em prazos mais longos.

É curioso notar que a crença de que os preços são mais difíceis de prever a longo prazo (períodos de meses ou anos) do que a curto prazo (períodos de dias ou semanas) contraria alguns dos resultados mais notórios na literatura empírica em Finanças. O menor nível de previsibilidade dos preços em prazos mais curtos é normalmente atribuído ao efeito de "ruído" (noise) que os investidores menos informados provocam nos preços. Se os noise traders podem fazer o preço afastar-se do seu nível de equilíbrio a curto prazo, a longo prazo a intervenção dos investidores mais bem informados parece fazer convergir os preços para a média. Como refere Mervyn King (2016: 122) num livro recente: "O mercado accionista é volátil e difícil de prever (senão impossível) em períodos curtos”. De facto, os estudos empíricos sugerem que a previsibilidade dos preços se manifesta num prazo de alguns meses e até um ano, como é o caso do efeito de momentum (Jegadeesh e Titman, 1993), ou até em prazos mais longos (entre três a cinco anos), como é o caso do chamado efeito de reversão para a média (Balvers et al., 2000). Em função da evidência empírica existente, pode então dizer-se que os preços são mais previsíveis a longo prazo do que em prazos mais curtos.

Porque não pensam assim os futuros investidores e porque parecem estar mais inclinados a achar que os preços num futuro distante são menos previsíveis? A nossa conjectura é a de que os indivíduos aplicam aos mercados financeiros, por analogia, o raciocínio normalmente utilizado 
em previsões mais gerais. Por exemplo, se alguém quiser estimar a probabilidade de uma guerra no Golfo Pérsico ou na Península Coreana, é de admitir que seja mais difícil levar a cabo previsões para um futuro longínquo do que para um futuro próximo. A curto prazo, as previsões terão naturalmente um grau de acerto superior, dado que se projecta simplesmente o passado recente num futuro imediato. Já previsões para prazos muito dilatados serão mais arriscadas. É natural que os factos que vão ocorrendo ao longo de um período prolongado de tempo interajam entre si de forma complexa, em sequências multiplicativas de efeitos não antecipados, fazendo com que previsões para períodos afastados do presente sejam mais fortemente afectados por factores de incerteza. Os nossos resultados sugerem que os futuros investidores aplicam uma heurística às previsões de evolução dos preços financeiros que se baseia no mesmo tipo de raciocínio, em contraste com alguns dos principais resultados da literatura em Finanças.

Normalmente, na investigação sobre a forma como as crenças e opiniões diferem entre diversos grupos demográficos de investidores procede-se ao controlo das estimativas com o recurso a variáveis financeiras. No caso do nosso estudo, no entanto, os respondentes constituem um grupo bastante homogéneo - são todos estudantes com interesse na área das Finanças. Por esse motivo apresentamos na Tabela 2 , à semelhança do ocorrido em estudos análogos, as comparações entre médias calculadas para dois subgrupos de respondentes. O objectivo é o de ilustrar diferenças significativas entre subgrupos de inquiridos.

A experiência de transacção parece introduzir algumas alterações na percepção que os investidores têm dos mercados financeiros. Embora os dois subgrupos (com experiência e sem experiência de transacção) acreditem que os mercados tendem para uma situação de equilíbrio, esta crença é mais acentuada para os investidores com experiência de transacção (média de $+0,61 v s .+0,25$ ). Apesar disso, a diferença na percentagem dos respondentes de cada grupo que concordam com a proposição correspondente $(55,3 \%$ vs. $48,2 \%)$ não é estatisticamente significativa aos níveis convencionais de significância.

As opiniões são semelhantes no que diz respeito às afirmações 2 e $4 \mathrm{~b}$. Os indivíduos sem experiência de transacção acreditam, na sua maioria $(54,7 \%)$, que os preços exibem um conjunto de padrões previsíveis nos preços enquanto a concordância com essa afirmação se manifesta em apenas $42,1 \%$ dos respondentes com experiência de transacção. A diferença é estatisticamente significativa a um nível de significância de $10 \%$. 


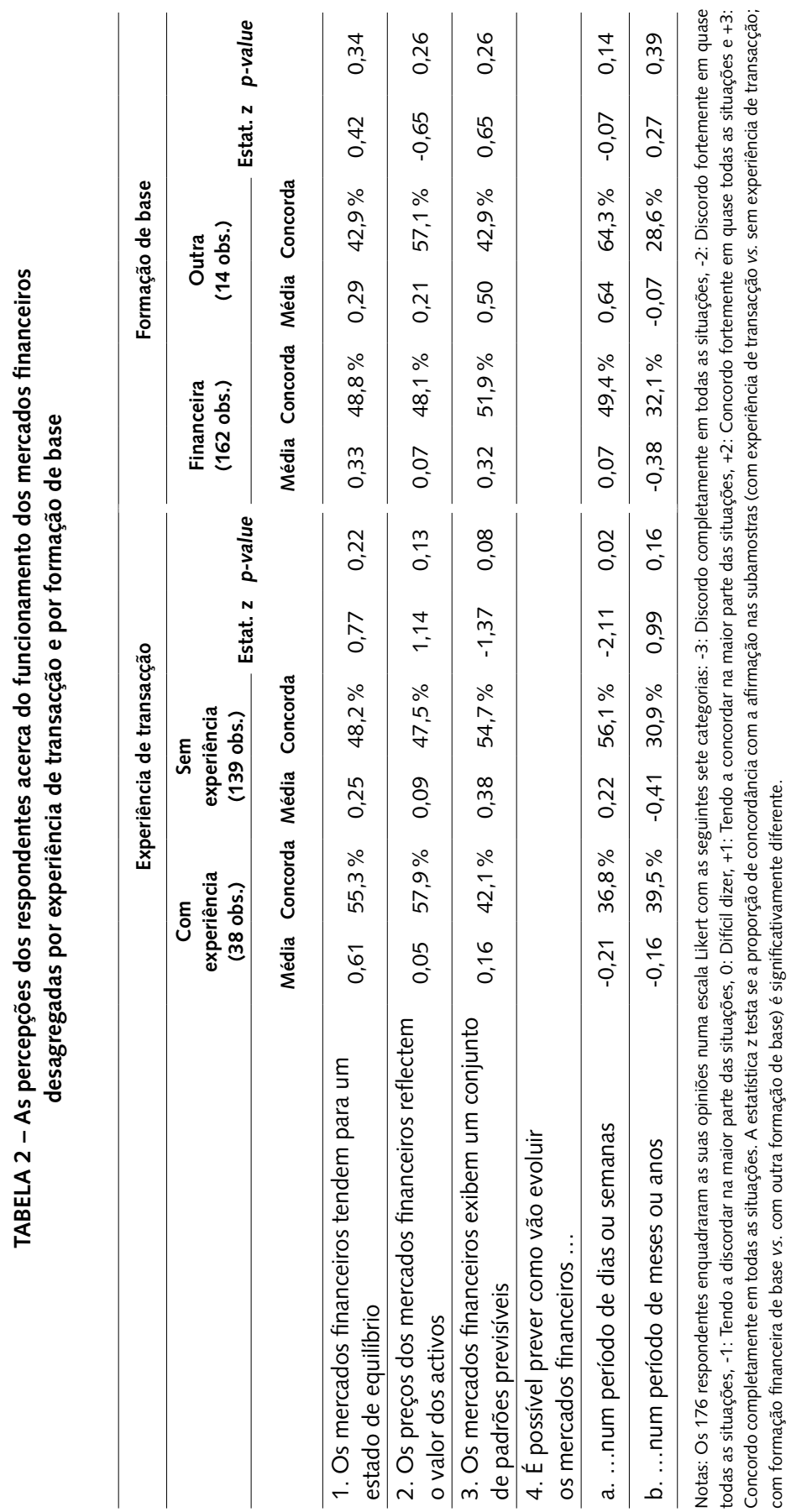


Já quanto à afirmação $4 a$ - "é possível prever como vão os preços evoluir num prazo de dias ou meses" - as opiniões médias têm sinal contrário: os respondentes que nunca transaccionaram acreditam, na sua maioria, na afirmação enquanto os inquiridos que já transaccionaram discordam dela $(+0,22$ vs. $-0,21)$. A diferença na percentagem dos indivíduos em cada subgrupo que concordam com a afirmação $(56,1 \%$ vs. 36,8\%) é estatisticamente significativa a um nível de $5 \%$ de significância. Os resultados nas afirmações 3 e 4 a sugerem que a experiência de transacção é relevante por colocar os investidores em contacto com a realidade do noise trading e com a consequente dificuldade de identificação de padrões nos preços e de previsão de evolução dos mercados no curto prazo.

De acordo com a teoria performativa a que já fizemos menção, os participantes de mercado produzem juízos de valor com base em disciplinas metrológicas. Como tem sido realçado por diversos sociólogos económicos que se inscrevem nessa corrente teórica (Abolafia, 1996; DiMaggio, 2002; Pixley, 2002; Davis, 2006), os actores sociais operam através da observação e da conformação com os objectivos definidos pela Ciência Económica e por outras áreas disciplinares relacionadas. Foi esta perspectiva que nos conduziu à desagregação dos resultados entre os respondentes com formação de base na área da Economia (o que inclui cursos de Economia, Gestão, Finanças e Contabilidade) e os respondentes provenientes de outras áreas de formação.

Considerando que os resultados acerca do impacto da área de formação de base dos estudantes devem ser analisados com cuidado dado o reduzido número de respondentes que apresenta formação fora da área de Economia e Gestão, é de referir contudo que esse factor não parece ser de fundamental importância nas concepções assumidas quanto ao funcionamento dos mercados financeiros. Uma conclusão similar tinha sido igualmente obtida por De Bondt (2005: 173), embora este autor tenha estudado apenas a diferença entre ter e não ter educação superior e não especificamente o efeito da área de formação.

Os inquiridos sem formação na área financeira estão mais convencidos do que os restantes de que é possível prever a evolução dos mercados em períodos curtos (dias ou semanas). No entanto, a diferença na percentagem dos respondentes em cada grupo que concordam com a afirmação correspondente não se revela estatisticamente significativa aos níveis convencionais de significância.

\section{b) Crenças e percepções acerca da regulação dos mercados financeiros}

Nas Tabelas 3 e 4 apresentam-se os resultados do inquérito no que diz respeito à opinião dos inquiridos acerca da regulação dos mercados financeiros. 
A Tabela 3 contém os resultados globais e a Tabela 4 contém os resultados desagregados em função da experiência de transacção e da área de formação.

Os dados que constam da Tabela 3 indicam que os futuros investidores não estão certos de que os mercados financeiros tenham desempenhado um papel positivo na economia (afirmação 5). A mediana das respostas situa-se na opinião neutral e a diferença entre a percentagem dos que concordam com a afirmação $(39,0 \%)$ e a dos que dela discordam $(35,0 \%)$ é de apenas 4 pontos percentuais.

Esta opinião é consistente com os resultados obtidos na afirmação 6 . Uma maioria muito significativa ( $65,5 \%$ do total) manifesta-se favorável a um endurecimento na regulação dos mercados. Do conjunto de opiniões apresentadas neste artigo, é nesta afirmação que a opinião dos inquiridos se apresenta mais clara. Isto é visível não apenas na forte intensidade de concordância com a afirmação (opinião média de $+0,92$ ) mas também no baixo nível verificado na dispersão das respostas $(1,55)$. A necessidade de reforço da regulação que se constata no nosso inquérito é consistente com a observada no inquérito levado a cabo por De Bondt (2005). Também os indivíduos estudados por este autor se afirmaram convictos de que a sociedade necessita de mudança e de que a regulação traz benefícios sociais.

Apesar de sentirem necessidade de maior regulação, os inquiridos, na sua globalidade, não pensam que os investidores devam ser penalizados face a outros grupos socioeconómicos como os trabalhadores, por exemplo. Confrontados com a possibilidade de os impostos aplicáveis às mais-valias financeiras serem mais elevados do que os que incidem sobre os salários, as opiniões dividem-se: $40,7 \%$ concordam, 36,2\% discordam. A média, a mediana e a moda das respostas situam-se num nível neutral. O valor observado na variância $(2,59)$ é o mais elevado de todas as afirmações apresentadas, o que evidencia a dispersão de opiniões quanto a esta matéria. É interessante estudar se alguma dessa dispersão de opiniões pode ser atribuída a factores como a experiência de transacção ou a formação de base dos inquiridos. Na Tabela 4 é possível observar que a avaliação que os inquiridos fazem do papel desempenhado pelos mercados financeiros não parece depender da sua experiência de transacção. $\mathrm{O}$ mesmo pode ser dito em relação às opiniões atinentes à necessidade de regulação dos mercados. Nestes dois casos, a diferença na percentagem dos indivíduos pertencentes a cada uma das subamostras que manifestaram concordância com as afirmações correspondentes não se revelou estatisticamente significativa aos níveis convencionais de significância. 
Já no que diz respeito à afirmação 7 , as opiniões são claramente divergentes. Os inquiridos que nunca transaccionaram manifestam-se favoráveis à aplicação de taxas de imposto superiores no caso das mais-valias financeiras $(44,6 \%$ de opiniões concordantes; $+0,13$ de opinião média), enquanto apenas uma minoria de respondentes com experiência de transacção $(26,3 \%)$ concorda com essa possibilidade $(-0,45$ de opinião média). A diferença nas percentagens de concordância entre os dois subgrupos mostra-se estatisticamente significativa a um nível de $5 \%$ de significância.

TABELA 3 - As percepções dos respondentes acerca da regulação dos mercados financeiros

\begin{tabular}{|c|c|c|c|c|c|c|c|}
\hline & Média & Mediana & Moda & Variância & Concorda & Discorda & Diferença \\
\hline $\begin{array}{l}\text { 5. Os mercados } \\
\text { financeiros têm } \\
\text { desempenhado um papel } \\
\text { positivo na economia do } \\
\text { meu país }\end{array}$ & 0,06 & 0,00 & 1,0 & 1,88 & $39,0 \%$ & $35,0 \%$ & 4,0 p.p. \\
\hline $\begin{array}{l}\text { 6. Os mercados } \\
\text { financeiros deveriam ser } \\
\text { mais regulados }\end{array}$ & 0,92 & 1,00 & 1,0 & 1,55 & $65,5 \%$ & $13,0 \%$ & 52,5 p.p. \\
\hline $\begin{array}{l}\text { 7. Os impostos sobre } \\
\text { mais-valias financeiras } \\
\text { deveriam ser mais } \\
\text { elevados do que os } \\
\text { impostos sobre os salários }\end{array}$ & 0,01 & 0,00 & 0,0 & 2,59 & $40,7 \%$ & $36,2 \%$ & 4,5 p.p. \\
\hline
\end{tabular}

Notas: Os 177 respondentes enquadraram as suas opiniões numa escala Likert com as seguintes sete categorias: -3: Discordo completamente em todas as situações, -2: Discordo fortemente em quase todas as situações, -1 : Tendo a discordar na maior parte das situações, 0 : Difícil dizer, +1 : Tendo a concordar na maior parte das situações, +2 : Concordo fortemente em quase todas as situações e +3: Concordo completamente em todas as situações. 
Crenças e percepções dos futuros investidores $\mid 43$

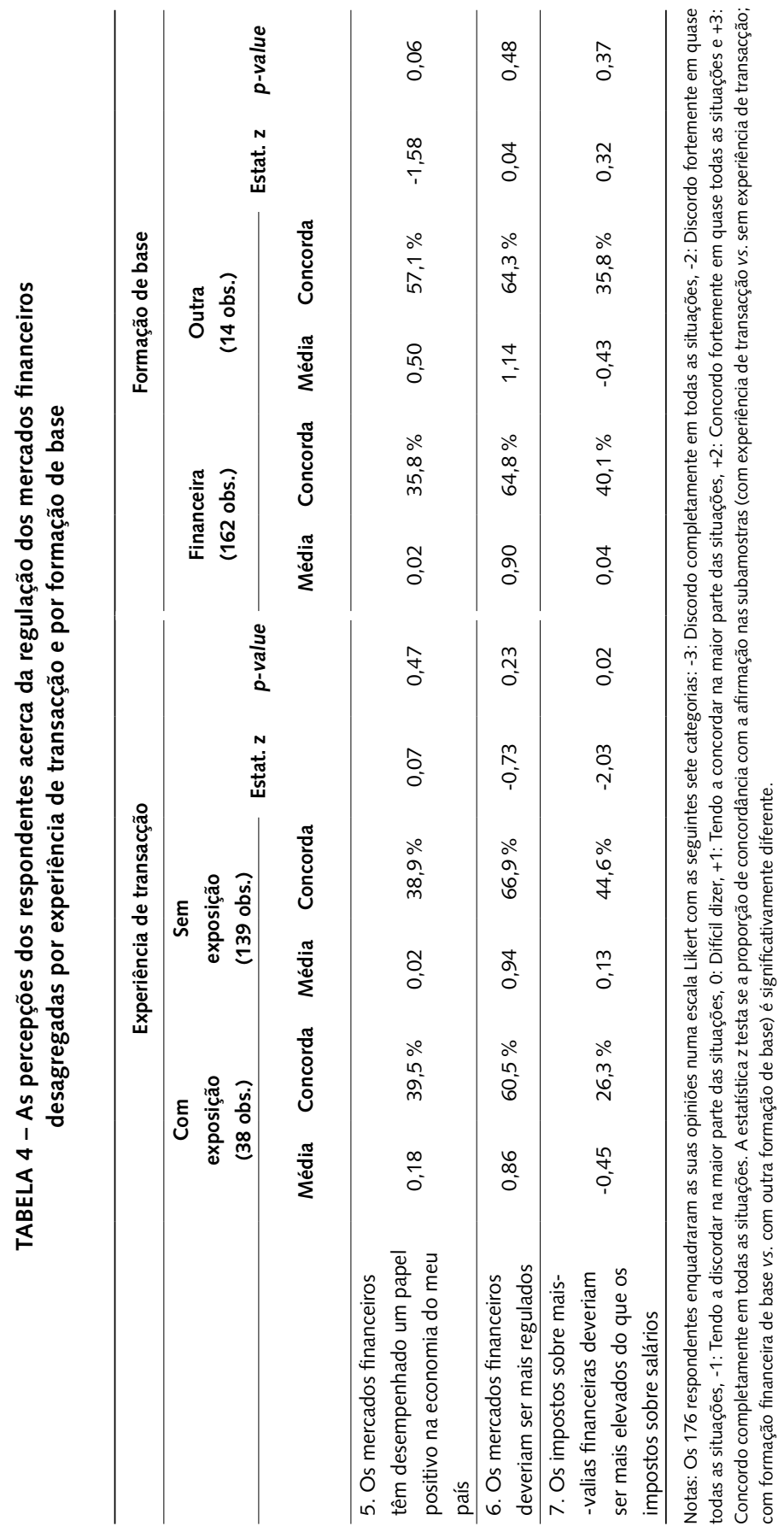


Estes resultados sugerem que a linha de fractura nas opiniões dos inquiridos se relaciona com os seus interesses pessoais, e não tanto com as opiniões que possam ter em relação à regulação em abstracto.

No que se refere às diferenças de percepções provocadas pelas diferentes áreas de formação dos inquiridos, o reduzido número de respondentes de áreas não-financeiras retira significado estatístico às diferenças encontradas. Apesar disso, uma formação de base na área financeira parece estar associada a um maior cepticismo dos respondentes acerca da contribuição dos mercados financeiros para o desenvolvimento da economia. Enquanto uma maioria dos indivíduos com formação em áreas não financeiras $(57,1 \%)$ atribui um papel positivo aos mercados financeiros nessa matéria, as opiniões concordantes encontram-se apenas em 35,8\% dos respondentes pertencentes ao subgrupo com formação em Finanças. Essa diferença revela-se estatisticamente significativa a um nível de significância de $10 \%$.

\section{Conclusão}

Conforme refere Krippner (2005: 173), "é difícil escapar à impressão de que estamos a viver actualmente num mundo dominado pelas Finanças”. Este extraordinário desenvolvimento das Finanças ao longo das últimas décadas tem sido acompanhado por um esforço notável no desenvolvimento da Sociologia da Economia e da Sociologia das Finanças (Smelser e Swedborg, 1994; Cetina e Preda, 2005).

No presente artigo seguimos o programa da Sociologia das Finanças para investigar, através do método de inquéritos, as crenças e percepções de um conjunto de 177 alunos de Finanças da Faculdade de Economia da Universidade do Porto (Portugal), entendidos como representativos da classe dos futuros investidores nos mercados financeiros.

As opiniões recolhidas revelam que os futuros investidores acreditam que os mercados financeiros tendem para um estado de equilíbrio. Este resultado é surpreendente tendo em atenção os padrões de evolução dos preços que têm caracterizado os activos financeiros nos anos mais recentes (Shiller, 2015). A dificuldade de revisão desta crença parece estar relacionada com a resistência dos mecanismos de divulgação de identidades e conceitos, maxime o sistema educacional, em actualizar os seus conceitos e valores. Este resultado parece assim dar razão a académicos como Mirowski (2013), que defendem que a crença no equilíbrio dos mercados se encontra tão enraizada na forma mentis dos indivíduos que as evidências que lhe são contrárias acabam por ser ignoradas através de um processo de dissonância cognitiva. A consequência é a de que os atores sociais não são capazes de retirar as lições devidas de episódios históricos como a crise financeira internacional. 
O nosso estudo dialoga com as teorias de performatividade nos mercados financeiros. De facto, os resultados obtidos evidenciam que instituições como os mercados financeiros que podem parecer à primeira vista como algo de natural ou com carácter meramente técnico, são na verdade instituições constituídas culturalmente e moldadas pelas relações sociais e pelo posicionamento relativo dos atores face a essas instituições. $\mathrm{Na}$ linha dos argumentos desenvolvidos por Fama $(1965,1970)$, pode ser antecipado que os preços reflictam de forma mais completa as parcelas de informação que os investidores acreditam ser mais importantes. Assim, dado que os indivíduos inquiridos no nosso estudo acreditam ser mais fácil prever como vão evoluir os mercados financeiros a curto prazo (período de dias ou semanas) do que a longo prazo (meses ou anos), é de esperar que sejam especialmente sensíveis aos factores capazes de afectar os preços em prazos mais curtos. Afinal, são esses elementos que os inquiridos acreditam poder proporcionar indicações acerca dos preços futuros. Em consequência, os preços de mercado tenderão a incorporar mais rapidamente esses factores. Ao contrário, os elementos que podem afectar os preços apenas a longo prazo tenderão a ser ignorados pelo facto de se acreditar não se poder actuar de forma lucrativa com base nesses factores. Por conseguinte, os preços incorporarão esses elementos de forma mais imperfeita ou limitada. Quer num caso quer noutro, as percepções dos indivíduos acerca do mercado podem repercutir-se nos preços observados.

Os inquéritos mostram também que, embora quase dois terços dos respondentes sejam a favor de maior regulação nos mercados financeiros, existem divergências significativas na forma de atingir esse objectivo e essas divergências parecem estar relacionadas com os interesses pessoais dos indivíduos. Seguindo então a lógica das teorias de performatividade, é possível entender a partir destes dados de que forma a variedade nas percepções dos atores sociais pode levar a condicionamentos na aplicação de estratégias públicas de regulação financeira.

Possíveis enviesamentos na selecção da amostra podem gerar receios quanto à validade externa dos nossos resultados. Esses receios colocam-se, é claro, não apenas no caso dos estudos que recorrem ao método de inquéritos. $\mathrm{Na}$ verdade, os procedimentos de selecção constituem uma parte intrínseca da generalidade dos estudos de campo e dos estudos experimentais. Apesar disso, julgamos que a validade externa do presente estudo é defensável pelo facto de os indivíduos da nossa amostra partilharem com a população alguns traços essenciais. A nossa amostra é constituída por indivíduos com notório interesse na área financeira e que frequentam um mestrado de continuidade, ou seja, um ciclo de estudos dirigido para 
os alunos recém-licenciados e que ainda não iniciaram a sua actividade profissional. Para além disso, existem indicações de que os indivíduos com educação superior se encontram sobrerrepresentados nos mercados financeiros (Campbell, 2006; Calvet et al., 2007).

Uma outra questão prende-se com o reduzido número de indivíduos com formação não-financeira incluídos na amostra, o que dificulta a percepção do efeito da área de formação nas opiniões dos futuros investidores. Esperamos que com a recolha de inquéritos adicionais a levar a cabo no futuro esta limitação da amostra possa ser ultrapassada.

Um dos pontos deixados em aberto por este estudo diz respeito ao grau de permanência, ao longo do tempo, dos resultados obtidos. Por um lado, tem sido defendido que na formação dos investidores se revela muito importante o seu relacionamento com o mercado de serviços de investimento. Este mercado proporciona conhecimento e ferramentas de análise dos mercados financeiros, contribui para criar um discurso acerca destas instituições e tece relações pessoais de carácter emocional (Roscoe, 2015). Ora, o desenvolvimento acelerado da indústria de serviços de investimento pode contribuir para alterar as percepções dos investidores, com consequências difíceis de prever. Por outro lado, no rescaldo da maior crise financeira internacional dos últimos 80 anos, diversos académicos e agentes políticos têm vindo a colocar em causa o papel que o sistema financeiro tem desempenhado ao longo das últimas décadas. Uma abundante literatura no domínio da chamada "financeirização das economias" tem proliferado ao longo dos anos mais recentes (nomeadamente Krippner, 2005; Lin e TomaskovicDevey, 2013; Rodrigues et al., 2016), com uma perspectiva essencialmente crítica acerca das transformações que se têm vindo a observar. Se essas críticas se irão algum dia reflectir na opinião dos investidores é uma questão que deverá merecer a atenção dos investigadores sociais do futuro.

Revisto por Rita Cabral

\section{Referências bibliográficas}

Abolafia, Mitchel Y. (1996), Making Markets: Opportunism and Restraint on Wall Street. Cambridge, MA: Harvard University Press.

Almenberg, Johan; Dreber, Anna (2015), "Gender, Stock Market Participation and Financial Literacy”, Economic Letters, 137, 140-142.

Arrondel, Luc; Debbich, Majdi; Savignac, Frédérique (2012), "Stockholding and Financial Literacy in the French Population", International Journal of Social Sciences and Humanity Studies, 4, 285-294. 
Aspers, Patrik (2007), “Theory, Reality, and Performativity in Markets”, American Journal of Economics and Sociology, 66, 379-398.

Balvers, Ronald; Wu, Yangru; Gilliland, Erik (2000), "Mean Reversion across National Stock Markets and Parametric Contrarian Investment Strategies", Journal of Finance, 55, 745-772.

Barber, Brad M.; Odean, Terrance (2000), “Trading Is Hazardous to Your Wealth: The Common Stock Investment Performance of Individual Investors", Journal of Finance, 55, 773-806.

Barber, Brad M.; Lee, Yi-Tsung; Liu, Yu-Jane; Odean, Terrance (2009), "Just how much Do Individual Investors Lose by Trading?”, Review of Financial Studies, 22, 609-632.

Boldyrev, Ivan; Svetlova, Ekaterina (orgs.) (2016), Enacting Dismal Science: New Perspectives on the Performativity of Economics. London: Palgrave-Macmillan.

Boyd, Brian (2010), On the Origin of Stories: Evolution, Cognition, and Fiction. Cambridge, MA: Harvard University Press.

Callon, Michel (1998), “The Embeddedness of Economic Markets in Economics”, in Michel Callon (org.), The Laws of the Markets. Oxford: Blackwell, 1-57.

Callon, Michel (2007), "What Does It Mean to Say that Economics is Performative?", in Donald MacKenzie; Fabian Muniesa; Lucia Siu (orgs.), Do Economists Make Markets? On the Performativity of Economics. Princeton, NJ: Princeton University Press, 311-357.

Calvet, Laurent; Campbell, John; Sodini, Paolo (2007), "Down or Out: Assessing the Welfare Costs of Household Investment Mistakes", Journal of Political Economy, 115, 707-747.

Campbell, John (2006), “Household Finance”, Journal of Finance, 61, 1553-1604.

Carruthers, Bruce G.; Kim, Jeong-Chul (2011), "The Sociology of Finance”, Annual Review of Sociology, 37, 239-259.

Cetina, Karin Knorr; Preda, Alex (orgs.) (2005), The Sociology of Financial Markets. Oxford: Oxford University Press.

Davis, Aeron (2006), “The Limits of Metrological Performativity: Valuing Equities in the London Stock Exchange", Competition \& Change, 10, 3-21.

De Bondt, Werner (2005), "The Values and Beliefs of European Investors”, in Karin Knorr Cetina; Alex Preda (orgs.), The Sociology of Financial Markets. Oxford: Oxford University Press, 163-186.

DiMaggio, Paul (2002), “Endogenizing 'Animal Spirits': Towards a Sociology of Collective Response to Uncertainty and Risk”, in Mauro F. Guillén; Randall Collins; Paula England; Marshall Meyer (orgs.), The New Economic Sociology: Developments in an Emerging Field. New York: Russell Sage Foundation, 79-100.

Dineen, Seán (2013), Probability Theory in Finance: A Matbematical Guide to the Black-Scholes Formula. Portland: American Mathematical Society [2. ${ }^{a}$ ed.]. 
Fama, Eugene (1965), “The Behaviour of Stock Market Prices”, Journal of Business, 38, 34-105.

Fama, Eugene (1970), "Efficient Capital Markets: A Review of Theory and Empirical Work", Journal of Finance, 25, 383-417.

Fine, Ben (2003), "Callonistics: A Disentanglement”, Economy and Society, 32, 478-484.

Frank, Robert H.; Gilovich, Thomas; Regan, Dennis T. (1993), “Does Studying Economics Inhibit Cooperation?”, Journal of Economic Perspectives, 7, 159-171.

Gardner, Howard (1985), The Mind's New Science: A History of the Cognitive Revolution. New York: Basic Books.

Ghoshal, Sumantra (2005), "Bad Management Theories Are Destroying Good Management Practices”, Academy of Management Learning \& Education, 4, 75-91. Ghoshal, Sumantra; Moran, Peter (1996), "Bad for Practice: A Critique of the Transaction Cost Theory", Academy of Management Review, 21, 13-47.

Goetzmann, William; Kumar, Alok (2008), “Equity Portfolio Diversification”, Review of Finance, 12, 433-463.

Jegadeesh, Narasimhan; Titman, Sheridan (1993), "Returns to Buying Winners and Selling Losers: Implications for Stock Market Efficiency”, Journal of Finance, 25, 65-91.

King, Mervyn (2016), The End of Alchemy: Money, Banking, and the Future of the Global Economy. New York: W. W. Norton \& Co.

Krippner, Greta (2005), “The Financialization of the American Economy”, Socio-Economic Review, 3, 173-209.

Lépinay, Vincent-Antonin (2011), Codes of Finance: Engineering Derivatives in a Global Bank. Princeton, MA: Princeton University Press.

Levine, Ross (2005), "Finance and Growth: Theory and Evidence", Handbook of Economic Growth, 1, 865-934.

Lin, Ken-Hou; Tomaskovic-Devey, Donald (2013), "Financialization and U.S. Income Inequality, 1970-2008”, American Journal of Sociology, 118, 1284-1329.

MacKenzie, Donald (2006), An Engine, not a Camera: How Financial Models Shape Markets. Cambridge, MA: MIT Press.

MacKenzie, Donald; Millo, Yuval (2003), “Constructing a Market, Performing Theory: The Historical Sociology of a Financial Derivatives Exchange”, American Journal of Sociology, 109, 107-145.

Mäki, Uskali (2013), "Performativity: Saving Austin from Mackenzie”, in Vassilios Karakostas; Dennis Dieks (orgs.), Perspectives and Foundational Problems in Philosopby of Science. Dordrecht: Springer, 443-453.

McCloskey, Deirdre (1992), "The Rhetoric of Finance”, in John Eatwell; Murray Milgate; Peter Newman (orgs.), The New Palgrave Dictionary of Money and Finance. London: Macmillan Press, 350-352.

Midgley, Mary (2004), The Myths We Live by. London/New York: Routledge. 
Miller, Daniel (2002), “Turning Callon the Right Way Up”, Economy and Society, 31, 218-233.

Mirowski, Philip (2013), Never Let a Serious Crisis Go to Waste: How Neoliberalism Survived the Financial Meltdown. London/New York: Verso.

Mirowski, Philip; Nik-Khah, Edward (2007), "Markets Made Flesh: Performativity, and a Problem in Science Studies, Augmented with Consideration of the FCC Auctions", in Donald MacKenzie; Fabien Muniesa; Lucia Siu (orgs.), Do Economists Make Markets? On the Performativity of Economics. Princeton, NJ: Princeton University Press, 190-224.

Mirowski, Philip; Nik-Khah, Edward (2008), "Command Performance: Exploring What STS Thinks It Takes to Build a Market”, in Trevor Pinch; Richard Swedberg (orgs.), Living in a Material World: Economic Sociology Meets Science and Technology Studies. Cambridge, MA: MIT Press, 89-128.

Pixley, Jocelyn (2002), "Finance Organisations, Decisions and Emotions”, British Journal of Sociology, 53, 41-65.

Rodrigues, João; Santos, Ana Cordeiro; Teles, Nuno (2016), A Financeirização do Capitalismo em Portugal. Coimbra: Actual Editora.

Roscoe, Philip (2015), “'Elephants Can't Gallop': Performativity, Knowledge and Power in the Market for Lay-investing”, Journal of Marketing Management, 31, 193-218.

Rubinson, Richard; Browne, Irene (1994), "Education and the Economy", in Neil J. Smelser; Richard Swedborg (orgs.), The Handbook of Economic Sociology. Princeton, NJ: Princeton University Press, 581-599.

Santos, Ana Cordeiro; Rodrigues, João (2009), "Economics as Social Engineering? Questioning the Performativity Thesis", Cambridge Journal of Economics, 33, 985-1000.

Shefrin, Hersh; Statman, Meir (2012), "Behavioral Finance in the Financial Crisis: Market Efficiency, Minsky, and Keynes”, in Alan S. Blinder; Andrew W. Lo; Robert M. Solow (orgs.), Rethinking the Financial Crisis. New York: Russell Sage Foundation, 99-135.

Shiller, Robert J. (2015), Irrational Exuberance. Princeton, NJ: Princeton University Press [3. ${ }^{a}$ ed.].

Siegel, Jeremy (2014), Stocks for the Long Run. New York: McGraw-Hill [5. ${ }^{a}$ ed.]. Simon, Herbert (1996), The Sciences of the Artificial. Cambridge, MA: MIT Press [3. ${ }^{\mathrm{a}}$ ed.].

Sjöberg, Lennart; Engelberg, Elisabeth (2009), "Attitudes to Economic Risk Taking, Sensation Seeking and Values of Business Students Specializing in Finance", Journal of Behavioral Finance, 10, 33-43.

Smelser, Neil J.; Swedborg, Richard (orgs.) (1994), The Handbook of Economic Sociology. Princeton, NJ: Princeton University Press.

Stiglitz, Joseph (1993), "The Role of the State in Financial Markets", Proceedings of the World Bank Annual Conference on Development Economics, 19-52. 
Stout, Lynn (1995), “Are Stock Markets Costly Casinos? Disagreement, Market Failure, and Securities Regulation”, Virginia Law Review, 81, 611-712.

Tarim, Emre (2012), "Storytelling and Structural Incoherence in Financial Markets", Journal of Interdisciplinary Economics, 24, 115-144.

Tuckett, David (2011), Minding the Markets: An Emotional Finance View of Financial Instability. London: Palgrave-Macmillan.

Vollmer, Hendrik; Mennicken, Andrea; Preda, Alex (2009), "Tracking the Numbers: Across Accounting and Finance, Organizations and Markets", Accounting, Organizations and Society, 34, 619-637.

Yoong, Joanne (2011), "Financial Illiteracy and Stock Market Participation: Evidence from the RAND American Life Panel”, in Olivia S. Mitchell; Annamaria Lusardi (orgs.), Financial Literacy: Implications for Retirement Security and the Financial Marketplace. Oxford/New York: Oxford University Press, 76-97.

Artigo recebido a 08.09.2017

Aprovado para publicação a 10.01.2019

\section{Júlio Lobão}

Faculdade de Economia da Universidade do Porto

Rua Dr. Roberto Frias, 4200-464 Porto, Portugal

Contacto: jlobao@fep.up.pt

ORCID: https://orcid.org/0000-0001-5896-9648

\section{Beliefs and Perceptions of Future Investors: A Contribution to Social Studies in Finance}

In the field of the Sociology of Finance, the beliefs and perceptions of individuals about to begin investing in financial markets has not been an issue thoroughly explored in the literature. In this article, we present new evidence about the opinions of future investors taken from a survey of 177 university students from 2014-2016. The results suggest that individuals have inconsistent perceptions about the financial markets; in addition, there is
Croyances et perceptions des futurs investisseurs: une contribution aux Études Sociales en Finance

Les croyances et les perceptions des individus qui sont sur le point de démarrer leur activité d'investissement sur les marchés financiers sont un sujet peu exploré par la Sociologie de la Finance. Dans cet article, nous présentons de nouvelles preuves sur les opinions des futurs investisseurs, en ayant recours à un questionnaire distribué à un groupe de 177 étudiants universitaires entre 2014 et 2016. Les résultats obtenus suggèrent que les individus ont 
conflict between the abstract need for regulation and the subjective consequences arising from the application of regulatory practices.

Keywords: economic regulation; financial markets; investment; sociological survey; Sociology of Finance. des perceptions inconsistantes sur les marchés financiers, mettant aussi en lumière un conflit entre le besoin abstrait de réglementation et les conséquences subjectives qui découlent de l'application de pratiques réglementaires.

Mots-clés: enquête sociologique; investissement; marchés financiers; régulation économique; Sociologie de la Finance. 
